Gazi University
Journal of Science
$\mathrm{http} / /$ dergipark.gov.tr/gujs

\title{
Measuring the Efficiency of Turkish State Universities Based on a Two-Stage DEA Model
}

\author{
Emre KOCAK *(D) , H. Hasan ORKCU (1) \\ Department of Statistics, Faculty of Science, Gazi University, Ankara, Turkey
}

\author{
Highlights \\ - This study focuses on independent and related two-stage envelopment analysis. \\ - Two-stage data envelopment analysis is applied to examine the performance of state universities. \\ - Universities are examined in terms of graduate education and research competency. \\ - This study agrees with the research universities determined by the Council of Higher Education.
}

\begin{tabular}{|c|}
\hline Article Info \\
\hline $\begin{array}{l}\text { Received: } 30 \text { Sep } 2020 \\
\text { Accepted: } 01 \text { Feb } 2021\end{array}$ \\
\hline Keywords \\
\hline $\begin{array}{l}\text { Two-stage data } \\
\text { envelopment analysis } \\
\text { Graduate education, } \\
\text { Scientific and } \\
\text { technological research } \\
\text { competency }\end{array}$ \\
\hline
\end{tabular}

\section{INTRODUCTION}

Apart from directing education and training life by finding out qualified brainpower, universities are the most important institutions for serving the society by producing new knowledge and technology in line with their research and development studies in areas such as health, engineering and technology, and contributing to globalization with the dissemination of these produced data. Due to the production of knowledge in universities in national and international terms and the emergence of qualified manpower with sufficient equipment for this production and the developments in science and technology, the importance of universities for humanity and the future has come to the fore more clearly.

Universities, more focused on education in the past, have entered the process that will contribute to social and economic development by turning their direction into research with the requirements of the time and the changing needs of the society. As in all areas of life, the social and economic changes caused by globalization have affected universities, causing them to change their organization chart and fields of efficiency. With the effect of these changes, competition between universities to reach the competency to meet the new education demands has increased. Universities had to search for new funds and resources due to the lack of financial resources caused by the rapidly increasing competition. Under these circumstances, universities aimed to create resources by increasing the production of knowledge and moving this 
production to commercial areas. As a consequence, the foundations of the concept of entrepreneurship have begun to be laid in universities because of the effort to adapt to change.

With the introduction of the concept of entrepreneurship in universities, universities have assigned various duties to develop knowledge and technology in research and development sectors such as education, health and agriculture, to increase cooperation with industry and to support regional development. Accordingly, research universities have been determined by the Council of Higher Education in Turkey. It is expected that research universities determined by the Council of Higher Education through certain criteria will have an efficient and productive structure in achieving their goals such as the production of qualified information produced by research and the development of cooperation with the public and industry.

During the determination of research universities, criteria such as the number of publications, number of citations, number of projects, project budget, number of patents and number of doctorate graduates have been used, and 15 research universities were selected, 10 of which are main and 5 are reserve universities. While the main research universities are Ankara University, Boğaziçi University, Erciyes University, Gazi University, Gebze Technical University, Hacettepe University, İstanbul University, İstanbul Technical University, İzmir Institute of Technology and Middle East Technical University, reserve universities are Çukurova University, Ege University, Selçuk University, Uludağ University and Yıldız Technical University.

The effects of these developments on universities are increasing day by day, and considerable progress has been made in terms of both education and science and technology. It has grown in importance to measure the effects of these advances on the performance of universities. Various methods have been used to measure the performance of universities in terms of both education and science and technology, and Data Envelopment Analysis (DEA) has been one of the most important methods. Besides, the performances of universities have been measured by using the two-stage DEA method, which is obtained by developing the models used in DEA over time. To examine the overall performance better and identify the causes of inefficiency, two-stage DEA model structure is considered instead of classical DEA.

For several years, great effort has been devoted to the study of the performance of universities. Kuah and Wong [1] established two different models for 30 universities in their study to evaluate the educational and research performance of universities. The inputs used in the model evaluating educational performance are the number of academic staff, number of students, average qualifications of students and university expenditures, respectively. Number of graduates, average results of graduates, graduation rate and employment rate of graduates are considered as output variables. In the other model in which the research performances of universities are measured, university expenditures, number of research staff, average qualifications of research staff, the number of research students and research grant are considered as input variables while number of graduates doing research, average results of graduates, number of awards and number of intellectual properties are considered as output variables.

Liang, Li, Cook, and Zhu [2] examined the performance of 50 universities in China in terms of education and research, and they established a two-stage network model. The input variables used to evaluate the educational efficiency of the universities considered are the fixed assets belonging to the university, the number of researchers, the number of graduates and the area of the university while the output variables are the number of SCI articles, the number of SCI citations and the number of national awards, respectively. While examining the efficiencies of universities in terms of research, the output variables used in the first stage of education stage were considered as input variables of the research stage and the research fund variable was used as output.

Lee and Worthington [3] established a two-stage network model to examine the performances of 37 universities in Australia in terms of both education and scholarship, and they took it as a basis between 2004-2011. In the research part, which is the first stage, the number of academic staff and the number of doctoral students is considered as input variables. The number of publications was used as the output of the first phase and also as the input of the second phase. In the second stage, efficiency scores of the universities were obtained by using the total income as output. 
This study, conducted by Xiong, Yang and Guan [4], is one of the few studies that examine the dynamic effects within the framework of the R\&D process. Based on the years of 2012-2015, the efficiency of 17 research universities in China was examined in two stages under the titles of research efficiencies and technology transfer. The number of $R \& D$ laboratories and $R \& D$ expenditures is considered as input variables used to examine the efficiency of research efficiencies based on universities, which is the first stage. The outputs of the first stage or intermediate outputs, which are also defined as the inputs of the second stage, are the number of patents and the number of published articles. The output used to evaluate the technology transfer efficiency of universities was considered as the income generated by licenses and subsequently, and the efficiency of universities in two different stages was examined.

Yang, Fukuyama, and Song [5] examined the production processes of 64 research universities in China between 2010-2013 with a two-phase network structure. While education and research efficiencies were examined in the first stage, the efficiency of science and technology achievements was examined in the second stage. In the first stage, R\&D budget, and state fund as input variables and SCI / SSCI number of publications, total number of students, total number of patents and number of other intellectual property as output variables were considered. In the second stage, the total number of patents and the number of other intellectual property which are the outputs of the first stage were used as inputs. Another input used at this stage is the number of staff working for the implementation of R\&D outputs and technology services. The only output of the second phase was used as revenue from technology transfer and patent sales.

In previous studies, the overall performances of universities in different countries were examined with different sub-processes and investigated with two-stage DEA models. Unlike these studies, the objective of this study is first to examine the performances of state universities in Turkey through different two-stage DEA models. Other objective of this study is to develop an alternative model that can be used in assignment the research universities determined by the Council of Higher Education. It has been preferred to use the two-stage DEA model instead of the classical DEA model to examine these contributions in detail.

In Section II, two-stage DEA will be discussed. Section III is devoted to the research findings and results. Section IV presents discussion and conclusion.

\section{TWO-STAGE DATA ENVELOPMENT ANALYSIS}

DEA, developed by Charnes et al. [6] to measure the relative efficiency of a series of decision-making units (DMUs), is a nonparametric method that shows how efficiently each DMU converts inputs into outputs against other DMUs. Another issue that is curious because of the analysis is the question of why inefficient DMUs are inefficient compared to efficient DMUs. Afterwards, studies have been made on the solution of this issue by separating the total efficiency to examine and determine the reasons why inefficient units are inefficient.

In this context, Banker, Charnes and Cooper [7] divided the total effectiveness of DMUs into scale efficiency and technical efficiency. Byrnes, Färe and Grosskoft [8] separated the density effect more than technical efficiency. Kao [9] converts total efficiency into the weighted arithmetic average of the effectiveness of individual outcomes. Apart from these decomposition studies, another decomposition type is related to production processes. While the resources used in these processes are defined as outputs for some sub-processes, the same resources can be defined as inputs for other sub-processes. The work of Färe and Grosskopf [10] and Seiford and Zhu [11] are some examples of this approach. The simplest example of such production processes is the tandem system where the entire production process consists of two subprocesses connected in series, that is, the process is divided into two parts. 


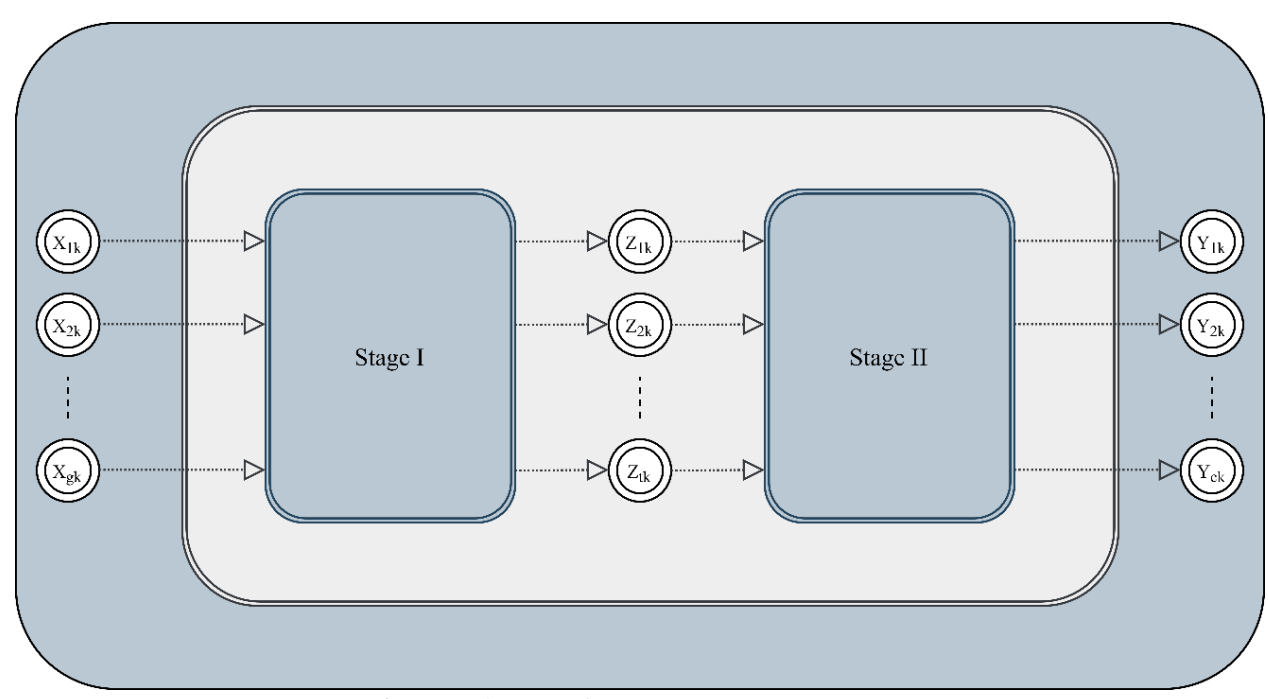

Figure 1. Production process

The production process shown in Figure 1 is called the basic two-stage system, and this system is also called two-stage DEA in the data envelopment methodology. Two-stage DEA should be differentiated from the studies which first applies a DEA model to measure the effectiveness of DMUs, and then applies a different analysis such as regression analysis in the second stage. In the first stage of the production process shown in Figure $1, X_{1 k}, X_{2 k}, \ldots, X_{g k}$ variables are considered as input variables, while the output of the second stage is $Y_{1 k}, Y_{2 k}, \ldots, Y_{c k} . Z_{1 k}, Z_{2 k}, \ldots, Z_{t k}$ variables are considered as the output variables of the first phase and also as the input variables of the second phase.

As the simplest way to investigate the performance of such a system, an independent model that evaluates the two parts as independent DMUs has been used to measure their effectiveness. The whole system can also be considered as a process called a black box, and its effectiveness can be measured by applying the CCR model, one of the traditional DEA models [12]. While calculating the efficiency of the DMUs, three different efficiency scores of the first, second and overall stages are calculated and shown in Table 1.

Table 1. To measure the efficiencies of overall stage, first stage and second stage for independent model

\begin{tabular}{|l|l|l|}
\hline Overall Stage & First Stage & Second Stage \\
\hline$E_{k}=\max \sum_{r=1}^{c} \mu_{r} Y_{r k}$ & $E_{k}^{1}=\sum_{p=1}^{t} w_{p} Z_{p k}$ & $E_{k}^{2}=\sum_{r=1}^{c} \mu_{r} Y_{r k}$ \\
$\sum_{i=1}^{g} v_{i} X_{i k}=1$ & $\sum_{i=1}^{g} v_{i} X_{i k}=1$ & $\sum_{p=1}^{t} w_{p} Z_{p k}=1$ \\
$\sum_{r=1}^{c} \mu_{r} Y_{r j}-\sum_{i=1}^{g} v_{i} X_{i j} \leq 0$ & $\sum_{p=1}^{t} w_{p} Z_{p j}-\sum_{i=1}^{g} v_{i} X_{i j} \leq 0$ & $\sum_{r=1}^{c} \mu_{r} Y_{r j}-\sum_{p=1}^{t} w_{p} Z_{p j} \leq 0$ \\
$\mu_{1}, \mu_{2}, \ldots, \mu_{c} \geq 0$ & $v_{1}, v_{2}, \ldots, v_{g} \geq 0$ & $\mu_{1}, \mu_{2}, \ldots, \mu_{c} \geq 0$ \\
$v_{1}, v_{2}, \ldots, v_{g} \geq 0$ & $w_{1}, w_{2}, \ldots, w_{t} \geq 0$ & $w_{1}, w_{2}, \ldots, w_{t} \geq 0$ \\
$(j=1,2, \ldots, n)$ & $(j=1,2, \ldots, n)$ & $(j=1,2, \ldots, n)$ \\
\hline
\end{tabular}


Kao and Hwang [13] wanted to investigate resources that cause inefficiencies in a production process by developing related models in their studies in addition to independent models used in two-stage DEA. In the related model developed, unlike the independent models, a serial relationship was created between the stages of the overall process, which are the sub-processes of the production process, and the overall efficiency was considered as a product of these two sub-processes.

$$
\begin{aligned}
& E_{k}=\sum_{r=1}^{c} \mu_{r} Y_{r k} / \sum_{i=1}^{g} v_{i} X_{i k} \\
& E_{k}^{1}=\sum_{p=1}^{t} w_{p} Z_{p k} / \sum_{i=1}^{g} v_{i} X_{i k} \\
& E_{k}^{2}=\sum_{r=1}^{c} \mu_{r} Y_{r k} / \sum_{p=1}^{t} w_{p} Z_{p k}
\end{aligned}
$$

With the help of these inequalities, there is a relationship between the overall efficiency and the efficiencies of the two sub-processes, $E_{k}=E_{k}^{1} * E_{k}^{2}$. The characteristic of this model is that the multiplier $w_{p}$, which relates to intermediate $Z_{p}$ as the output of the first stage, must be the same as the input of the second stage. The models in which the efficiency of the related model is calculated are shown as follows:

$$
\begin{aligned}
& E_{k}=\max \sum_{r=1}^{c} \mu_{r} Y_{r k} \\
& \sum_{i=1}^{g} v_{i} X_{i k}=1 \\
& \sum_{r=1}^{c} \mu_{r} Y_{r j}-\sum_{i=1}^{g} v_{i} X_{i j} \leq 0 \\
& \sum_{p=1}^{t} w_{p} Z_{p j}-\sum_{i=1}^{g} v_{i} X_{i j} \leq 0 \\
& \sum_{r=1}^{c} \mu_{r} Y_{r j}-\sum_{p=1}^{t} w_{p} Z_{p j} \leq 0 \\
& \mu_{1}, \mu_{2}, \ldots, \mu_{c} \geq 0 \\
& v_{1}, v_{2}, \ldots, v_{g} \geq 0 \\
& w_{1}, w_{2}, \ldots, w_{t} \geq 0 \\
& (j=1,2, \ldots, n)
\end{aligned}
$$

In both independent and related model,

$E_{k}$ : The efficiency score of the overall stage

$E_{k}^{1}$ : The efficiency score of the first stage

$E_{k}^{2}$ : The efficiency score of the second stage

$\mu_{r}$ : In the second stage, the weight given to the $\mathrm{r}^{\text {th }}$ output by $\mathrm{DMU}_{\mathrm{k}}$

$v_{\mathrm{i}}$ : In the first stage, weight given to $\mathrm{i}^{\text {th }}$ input by $\mathrm{DMU}_{\mathrm{k}}$

$w_{p}$ : In the first stage, weight given to $\mathrm{p}^{\text {th }}$ output by $\mathrm{DMU}_{\mathrm{k}}$ or in the second stage, weight given to $\mathrm{p}^{\text {th }}$ input by $\mathrm{DMU}_{\mathrm{k}}$

$Y_{r k}$ : In the second stage, $\mathrm{r}^{\text {th }}$ output produced by $\mathrm{DMU}_{\mathrm{k}}$ 
$X_{i k}:$ In the first stage, $\mathrm{i}^{\text {th }}$ input produced by $\mathrm{DMU}_{\mathrm{k}}$

$Z_{p k}$ : In the first stage, $\mathrm{p}^{\text {th }}$ output produced by $\mathrm{DMU}_{\mathrm{k}}$ or in the second stage, $\mathrm{p}^{\text {th }}$ input produced by $\mathrm{DMU}$

$Y_{r j}: \mathrm{r}^{\text {th }}$ output produced by $\mathrm{DMU}_{\mathrm{j}}$

$X_{i j}: \mathrm{i}^{\text {th }}$ input produced by $\mathrm{DMU}_{\mathrm{j}}$

$Z_{p j}$ : In the first stage, $\mathrm{p}^{\text {th }}$ output produced by $\mathrm{DMU}_{\mathrm{j}}$ or in the second stage, $\mathrm{p}^{\text {th }}$ input produced by $\mathrm{DMU}_{\mathrm{j}}$.

\section{THE RESEARCH FINDINGS AND RESULTS}

This study, measuring the performances of 53 state universities established before 2000 in Turkey, examines graduate education performances of state universities in the first stage, and scientific and technological research competency performances of the same state universities in the second stage. The input variables used in the first stage to measure graduate education performances are considered as the number of faculty members and the ratio of the number of graduate students to the total number of students. The educational budget per faculty member and the number of articles is used as input variables for the second phase, in which scientific and technological research competency performances are measured, or output variables for the first phase. The outputs of the second phase are the number of citations, the number of graduate doctor students, the number of proposed projects, the number of supported projects and the project budget variables. The variables used in the production process and stages of the model are shown in Figure 2, and the descriptive statistics values of these variables are given in Table 2.

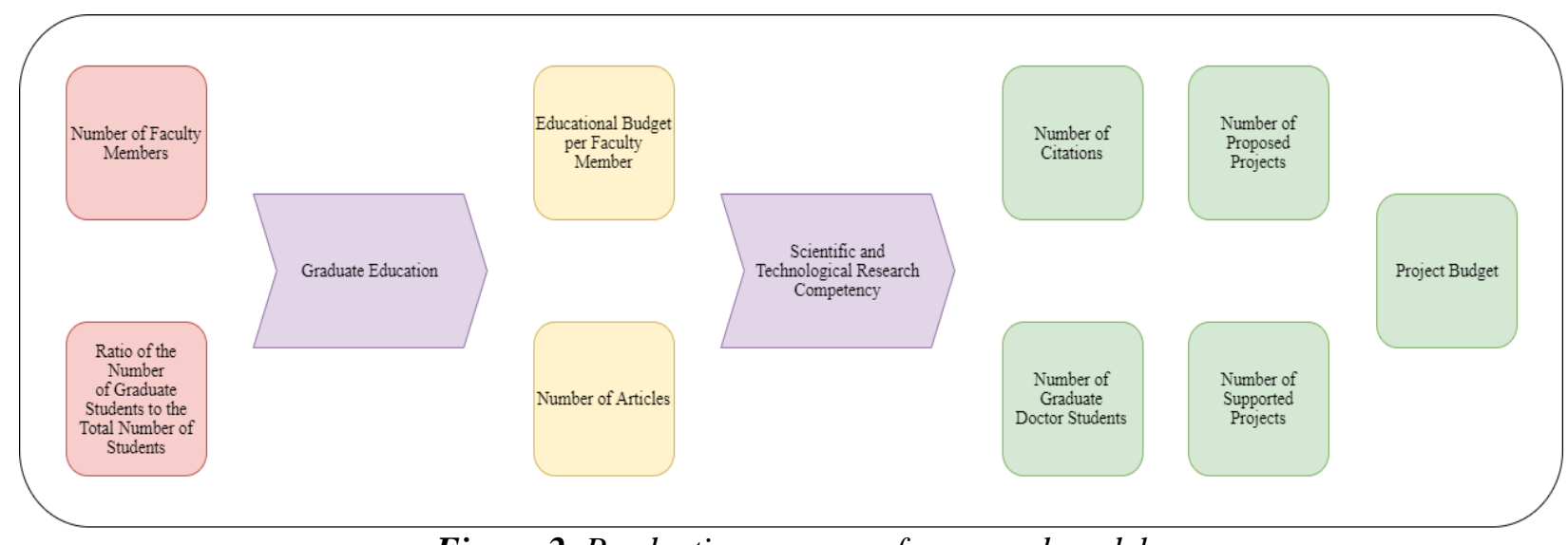

Figure 2. Production process of proposed model

Table 2. Descriptive statistics

\begin{tabular}{c|cccc}
\hline Variables & Mean & $\begin{array}{c}\text { Standard } \\
\text { Deviation }\end{array}$ & Minimum & $\begin{array}{c}\text { Maximu } \\
\text { m }\end{array}$ \\
\hline Number of Faculty Members & 882,283 & 500,702 & 141 & 2915 \\
\hline Number of Graduate Students & 7747,906 & 6234,140 & 1567 & 29618 \\
\hline Total Number of Students & 46519,679 & 23155,192 & 4659 & 118579 \\
\hline Education Budget per Faculty Member (Thousand TL) & 324,150 & 51,421 & 240,150 & 500,940 \\
\hline Number of Articles & 696 & 508,517 & 75 & 2346 \\
\hline Number of Citations & 949,472 & 834,644 & 127 & 3896 \\
\hline Number of Graduate Doctors & 98,680 & 107,816 & 9 & 468 \\
\hline Number of Proposed Projects & 124 & 90,686 & 5 & 382 \\
\hline Number of Supported Projects & 18,491 & 18,825 & 1 & 81 \\
\hline Project Budget (Million TL) & 6,391 & 7,670 & 0,190 & 34,870 \\
\hline
\end{tabular}

The efficiency results obtained from these stages in which the graduate education and scientific and technological research competence performances of state universities are measured with the help of the independent and related two-stage DEA model are given in Table 3. 
Table 3. Efficiency scores of state universities for independent and related model

\begin{tabular}{|c|c|c|c|c|c|c|}
\hline \multirow{2}{*}{ University } & \multicolumn{3}{|c|}{ Independent Model } & \multicolumn{3}{|c|}{ Related Model } \\
\hline & E0 & E1 & E2 & E0 & E1 & $\mathbf{E 2}$ \\
\hline Abant İzzet Baysal & 0,209 & 0,291 & 0,660 & 0,191 & 0,289 & 0,660 \\
\hline Adnan Menderes & 0,292 & 0,273 & 0,916 & 0,243 & 0,265 & 0,916 \\
\hline Afyon Kocatepe & 0,135 & 0,304 & 0,533 & 0,134 & 0,252 & 0,533 \\
\hline Akdeniz & 0,491 & 0,404 & 0,920 & 0,363 & 0,395 & 0,919 \\
\hline Anadolu & 0,383 & 0,509 & 0,833 & 0,302 & 0,411 & 0,734 \\
\hline Ankara & 1 & 0,804 & 1 & 0,804 & 0,804 & 1 \\
\hline Atatürk & 0,780 & 0,500 & 1 & 0,464 & 0,464 & 1 \\
\hline Balıkesir & 0,259 & 0,311 & 0,719 & 0,159 & 0,221 & 0,719 \\
\hline Boğaziçi & 1 & 0,977 & 1 & 0,797 & 0,797 & 1 \\
\hline Bülent Ecevit & 0,158 & 0,328 & 0,370 & 0,120 & 0,323 & 0,370 \\
\hline Cumhuriyet & 0,204 & 0,304 & 0,586 & 0,171 & 0,294 & 0,581 \\
\hline Çanakkale Onsekiz Mart & 0,327 & 0,283 & 0,979 & 0,277 & 0,283 & 0,979 \\
\hline Çukurova & 0,465 & 0,520 & 0,736 & 0,382 & 0,520 & 0,735 \\
\hline Dicle & 0,251 & 0,333 & 0,481 & 0,139 & 0,290 & 0,481 \\
\hline Dokuz Eylül & 0,576 & 0,530 & 0,874 & 0,456 & 0,529 & 0,862 \\
\hline Dumlupinar & 0,170 & 0,359 & 0,523 & 0,148 & 0,289 & 0,511 \\
\hline Ege & 0,982 & 0,603 & 1 & 0,603 & 0,603 & 1 \\
\hline Erciyes & 0,540 & 0,480 & 0,893 & 0,429 & 0,480 & 0,893 \\
\hline Eskişehir Osmangazi & 0,389 & 0,516 & 0,679 & 0,332 & 0,489 & 0,678 \\
\hline Firat & 0,411 & 0,444 & 0,810 & 0,350 & 0,432 & 0,809 \\
\hline Galatasaray & 0,662 & 1 & 1 & 0,286 & 0,291 & 0,983 \\
\hline Gazi & 1 & 0,792 & 1 & 0,792 & 0,792 & 1 \\
\hline Gaziantep & 0,462 & 0,530 & 0,702 & 0,349 & 0,498 & 0,702 \\
\hline Gaziosmanpaşa & 0,402 & 0,404 & 0,809 & 0,299 & 0,369 & 0,809 \\
\hline Gebze Technical & 1 & 1 & 1 & 1 & 1 & 1 \\
\hline Hacettepe & 1 & 1 & 1 & 1 & 1 & 1 \\
\hline Harran & 0,135 & 0,310 & 0,440 & 0,120 & 0,275 & 0,437 \\
\hline İnönü & 0,445 & 0,413 & 0,711 & 0,291 & 0,410 & 0,710 \\
\hline İstanbul & 1 & 1 & 1 & 0,975 & 0,975 & 1 \\
\hline İstanbul Technical & 1 & 1 & 1 & 1 & 1 & 1 \\
\hline İzmir Institute of Technology & 1 & 1 & 1 & 1 & 1 & 1 \\
\hline Kafkas & 0,467 & 0,410 & 0,758 & 0,311 & 0,410 & 0,758 \\
\hline Kahramanmaraş Sütçü İmam & 0,330 & 0,373 & 1 & 0,252 & 0,252 & 1 \\
\hline Karadeniz Technical & 0,626 & 0,450 & 1 & 0,450 & 0,450 & 1 \\
\hline Kırıkkale & 0,183 & 0,297 & 0,454 & 0,129 & 0,283 & 0,454 \\
\hline Kocaeli & 0,341 & 0,365 & 0,793 & 0,286 & 0,361 & 0,793 \\
\hline Manisa Celal Bayar & 0,253 & 0,330 & 0,687 & 0,224 & 0,326 & 0,687 \\
\hline Marmara & 0,662 & 0,644 & 0,950 & 0,586 & 0,622 & 0,942 \\
\hline Mersin & 0,398 & 0,385 & 0,835 & 0,320 & 0,384 & 0,835 \\
\hline Middle East Technical & 1 & 1 & 1 & 1 & 1 & 1 \\
\hline Mimar Sinan Fine Arts & 0,513 & 0,337 & 1 & 0,282 & 0,282 & 1 \\
\hline Muğla Sıtkı Koçman & 0,209 & 0,304 & 0,619 & 0,187 & 0,302 & 0,619 \\
\hline Mustafa Kemal & 0,156 & 0,318 & 0,506 & 0,140 & 0,276 & 0,506 \\
\hline Ondokuz Mayıs & 0,413 & 0,419 & 0,767 & 0,317 & 0,413 & 0,767 \\
\hline Ömer Halisdemir & 0,173 & 0,260 & 0,725 & 0,171 & 0,243 & 0,706 \\
\hline Pamukkale & 0,224 & 0,334 & 0,601 & 0,197 & 0,328 & 0,601 \\
\hline Sakarya & 0,477 & 0,393 & 0,995 & 0,370 & 0,384 & 0,962 \\
\hline Selçuk & 0,524 & 0,496 & 0,760 & 0,365 & 0,491 & 0,745 \\
\hline Süleyman Demirel & 0,509 & 0,408 & 1 & 0,385 & 0,385 & 1 \\
\hline Trakya & 0,170 & 0,292 & 0,458 & 0,121 & 0,265 & 0,458 \\
\hline Uludă̆ & 0,405 & 0,417 & 0,778 & 0,310 & 0,410 & 0,755 \\
\hline Yıldız Technical & 0,761 & 0,659 & 1 & 0,655 & 0,655 & 1 \\
\hline Yüzüncü Yıl & 0,229 & 0,367 & 0,553 & 0,191 & 0,347 & 0,551 \\
\hline
\end{tabular}


According to the results of independent two-stage DEA analysis given in Table 3, Gebze Technical, Hacettepe, İstanbul Technical, İzmir Institute of Technology, Middle East Technical, İstanbul and Galatasaray have been determined as efficient universities in terms of both graduate education performances and, scientific and technological research competency performances. In addition to these, Ankara, Boğaziçi, Gazi, Yıldız Teknik, Ege, Atatürk, Karadeniz Teknik, Süleyman Demirel, Mimar Sinan Fine Arts and Kahramanmaraş Sütçü İmam have been determined as efficient universities only in terms of their scientific and technological research qualification performances.

According to the results of related two-stage DEA, while Gebze Technical, Hacettepe, İstanbul Technical, İzmir Institute of Technology and Middle East Technical have been determined as efficient universities in terms of both graduate education performances and, scientific and technological research competency performances. In addition to these, İstanbul, Ankara, Boğaziçi, Gazi, Yıldız Technical, Ege, Atatürk, Karadeniz Technical, Süleyman Demirel, Mimar Sinan Fine Arts and Kahramanmaraş Sütçü İmam have been determined as efficient universities only in terms of scientific and technological research competency performances.

When the overall performances of universities are examined; Gebze Technical, Hacettepe, İstanbul Technical, İzmir Institute of Technology and Middle East Technical have been determined as efficient universities both independent model and related model. Furthermore, İstanbul, Ankara, Boğaziçi and Gazi have been determined as efficient universities only in terms of independent model.

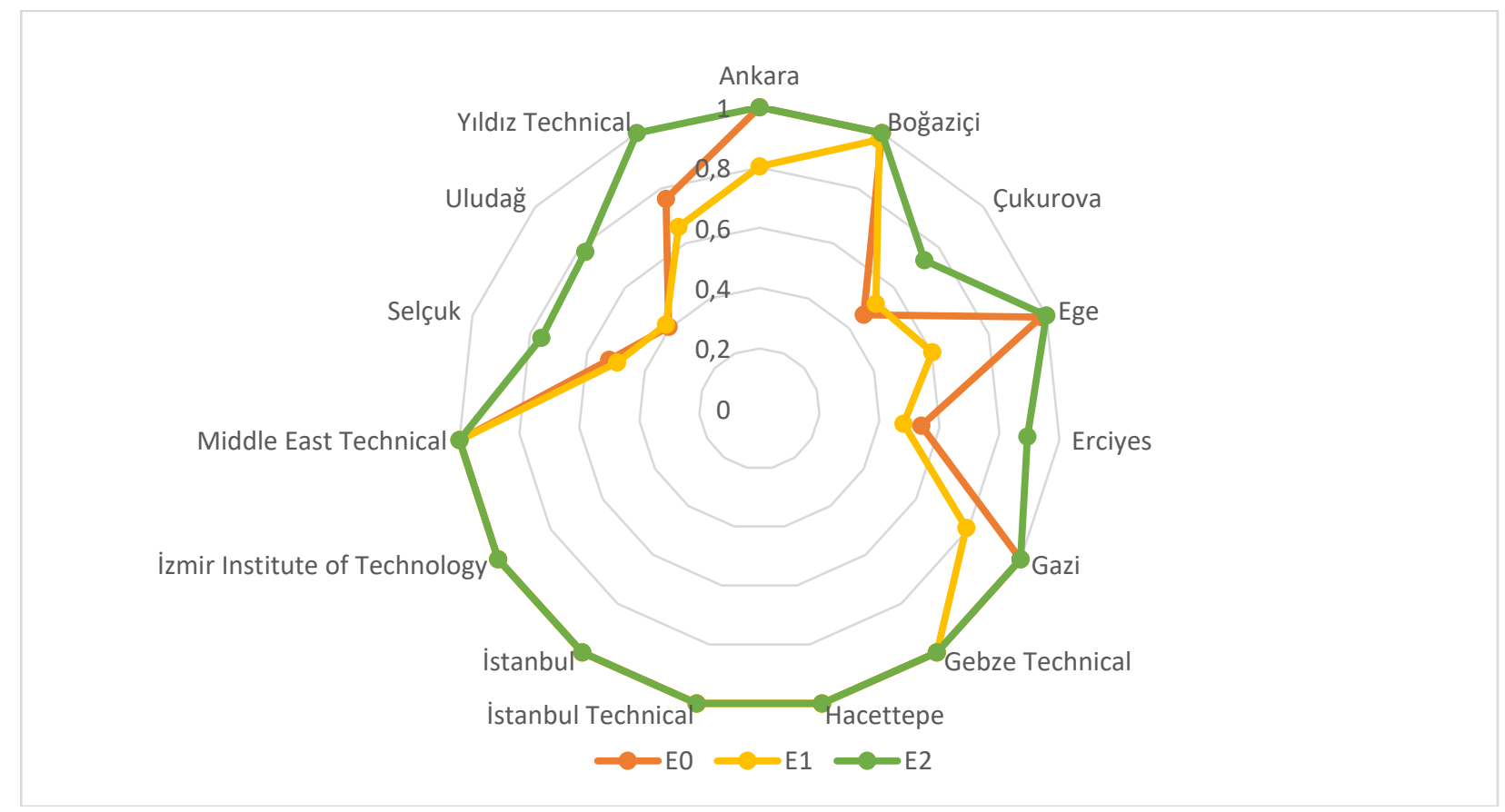

Figure 3. Efficiency scores of main and reserve research universities for independent model

According to Figure 3, which includes main research universities and reserve research universities and shows the efficiency scores of the stages of the independent model, Gebze Technical, Hacettepe, İstanbul Technical, İstanbul, İzmir Institute of Technology and Middle East Technical have been found efficient universities in all three stages. Furthermore, while Ankara, Boğaziçi and Gazi are efficient universities in the overall stage and in the second stage, Ege and Y1ldiz Technical are found as efficient universities only in the second stage. Nevertheless, Çukurova University, Erciyes University, Selçuk and Uludağ could not take place as efficient universities at any stage. 


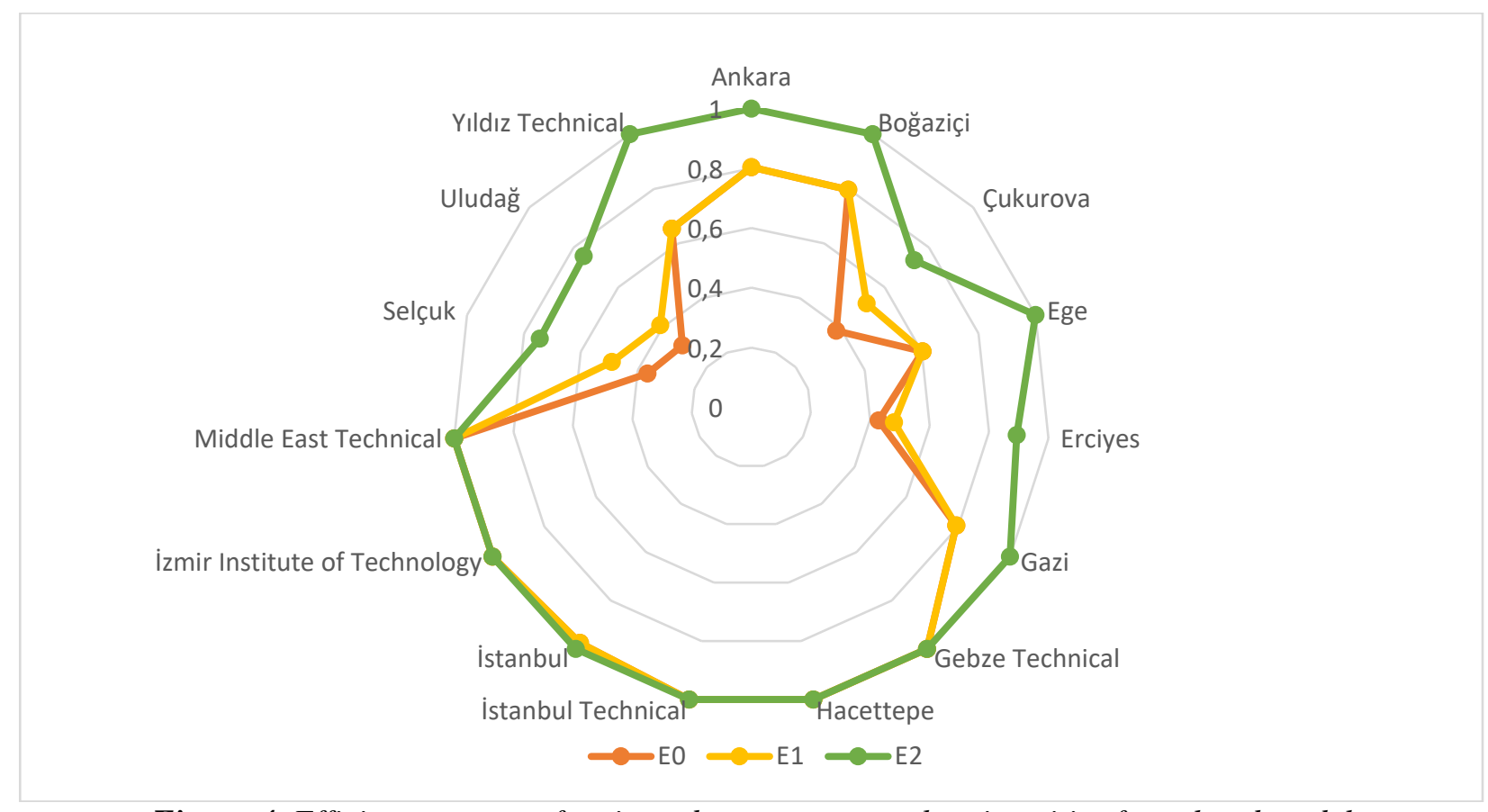

Figure 4. Efficiency scores of main and reserve research universities for related model

According to Figure 4, which includes main research universities and reserve research universities and shows the efficiency scores of the stages of the related model, Gebze Technical, Hacettepe, İstanbul Technical, İzmir Institute of Technology and Middle East Technical have been found efficient universities in all three stages. Furthermore, while Ankara, Boğaziçi, Ege, Gazi, İstanbul and Yıldız Technical are efficient universities only in the second stage, Çukurova, Erciyes, Selçuk and Uludağ could not take place as efficient universities at any stage.

\section{DISCUSSION AND CONCLUSION}

In DEA method, which is a non-parametric linear programming problem, the efficiency scores of each DMU are found by maximizing the ratio of the total weighted outputs to the total of the weighted inputs. According to the efficiency scores obtained, the related units are named as efficient or inefficient DMU. The main question here is to what extent inefficient DMUs are inefficient compared to efficient DMUs. To answer this question, the system was divided into two stages and two-stage DEA models with different structures were proposed.

With the help of independent and related models, the most basic models of two-stage DEA models, the performances of state universities in Turkey have been examined in this study. To examine the performances of universities in a more detailed way, a two-stage system was considered, and in these stages, graduate education and scientific and technological research competency performances have been discussed, respectively. When the efficiency scores of both stages and overall stages of independent and related models are examined, Gebze Technical, Hacettepe, İstanbul Technical, İzmir Institute of Technology and Middle East Technical have been found as efficient universities.

The most remarkable result to emerge from the data is that when the cities where these research universities are located are examined, it is observed that their common characteristics are that they are all metropolitan cities and developed in the field of industry. In addition to these features, the number of R\&D centers, design centers and technology development zones in these cities is considerably higher than those in the cities where other universities are located. For this reason, these universities stand out compared to the universities in other provinces. It is necessary to invest in cities that are lagging behind in these fields of science and technology and to increase their interactions with universities so that non-research universities can compete with the others. 
Since the number of undergraduate students is higher than the number of graduate students, more time cannot be allocated to research and projects in inefficient universities. Therefore, the importance of quality graduate education should be increased by increasing the ratio of graduate students to total number of students. In addition to these, it is necessary to produce quality publications and projects by focusing on the graduate education of universities.

It is important to note that nine of the top ten universities in each stage of independent and related models are main research universities determined by the Council of Higher Education. In other words, our study is in line with the research universities determined by the Council of Higher Education through certain criteria. Galatasaray is placed in graduate education stage and, Ege is placed in the overall and scientific and technological research competency stage in independent model while Yildız Technical is placed all stage in related model instead of Erciyes. Ege and Yildiz Technical, which replaced the Erciyes, are also reserve research universities except Galatasaray. Therefore, the proposed model in this study can be considered as a method to be applied to identify research universities.

\section{CONFLICTS OF INTEREST}

No conflict of interest was declared by the authors.

\section{REFERENCES}

[1] Kuah, C. T., Wong, K. Y., "Efficiency assessment of universities through data envelopment analysis", Procedia Computer Science, 3: 499-506, (2011).

[2] Liang, L., Li, Z. Q., Cook, W. D., Zhu, J., "Data envelopment analysis efficiency in two-stage networks with feedback", IIE Transactions, 43(5): 309-322, (2011).

[3] Lee, B. L., Worthington, A. C., "A network DEA quantity and quality-orientated production model: An application to Australian university research services", Omega, 60: 26-33, (2016).

[4] Xiong, X., Yang, G. L., Guan, Z. C., “Assessing R\&D efficiency using a two-stage dynamic DEA model: A case study of research institutes in the Chinese Academy of Sciences", Journal of Informetrics, 12(3): 784-805, (2018).

[5] Yang, G. L., Fukuyama, H., Song, Y. Y., "Measuring the inefficiency of Chinese research universities based on a two-stage network DEA model", Journal of Informetrics, 12(1): 10-30, (2018).

[6] Charnes, A., Cooper, W. W., Rhodes, E., "Measuring the efficiency of decision making units", European Journal of Operational Research, 2(6): 429-444, (1978).

[7] Banker, R. D., Charnes, A., Cooper, W. W., "Some models for estimating technical and scale inefficiencies in data envelopment analysis", Management Science, 30(9): 1078-1092, (1984).

[8] Byrnes, P., Färe, R., Grosskopf, S., "Measuring productive efficiency: an application to Illinois strip mines", Management Science, 30(6): 671-681, (1984).

[9] Kao, C., "Some properties of Pareto efficiency under the framework of data envelopment analysis", International Journal of Systems Science, 26(9): 1549-1558, (1995).

[10] Färe, R., Grosskopf, S., "Productivity and intermediate products: A frontier approach", Economics Letters, 50(1): 65-70, (1996). 
[11] Seiford, L. M., Zhu, J., "Profitability and marketability of the top 55 US commercial banks", Management Science, 45(9): 1270-1288, (1999).

[12] Kao, C., "Network data envelopment analysis", Switzerland: Springer International Publishing, (2017).

[13] Kao, C., Hwang, S. N., "Efficiency decomposition in two-stage data envelopment analysis: An application to non-life insurance companies in Taiwan", European Journal of Operational Research, 185(1): 418-429, (2008). 